\title{
3D Printing Engineered Multi-porous Cu Microelectrodes with In Situ Electro-Oxidation Growth of CuO Nanosheets for Long Cycle, High Capacity and Large Rate Supercapacitors
}

\author{
Tao Liu ${ }^{1} \cdot$ Yuejiao Chen ${ }^{1} \cdot$ Libao Chen $^{1}$ \\ Received: 9 April 2020 / Revised: 27 April 2020 / Accepted: 11 May 2020 / Published online: 30 June 2020 \\ (c) The Chinese Society for Metals (CSM) and Springer-Verlag GmbH Germany, part of Springer Nature 2020
}

\begin{abstract}
Developing excellent pseudocapacitive electrodes with long cycle, high areal capacity and large rate has been challenged. 3D printing is an additive manufacture technique that has been explored to construct microelectrodes of arbitrary geometries for high-energy-density supercapacitors. In comparison with conventional electrodes with uncontrollable geometries and architectures, 3D-printed electrodes possess unique advantage in geometrical shape, mechanical properties, surface area, especially in ion transport and charge transfer. Thus, a desirable 3D electrode with ordered porous structures can be elaborately designed by $3 \mathrm{D}$ printing technology for improving electrochemical capacitance and rate capability. In this work, a designed, monolithic and ordered multi-porous 3D Cu conductive skeleton was manufactured through 3D direct ink writing technique and coated with $\mathrm{CuO}$ nanosheet arrays by an in situ electro-oxidation treatment. Benefiting from the highly ordered multiporous nature, the 3D-structured skeleton can effectively enlarge the surface area, enhance the penetration of electrolyte and facilitate fast electron and ion transport. As a result, the 3D-printed $\mathrm{Cu}$ deposited with electro-oxidation-generated $\mathrm{CuO}$ (3DP $\mathrm{Cu} @ \mathrm{CuO})$ electrodes demonstrates an ultrahigh areal capacitance of $1.690 \mathrm{~F} \mathrm{~cm}^{-2}\left(38.79 \mathrm{~F} \mathrm{~cm}^{-3}\right)$ at a large current density of $30 \mathrm{~mA} \mathrm{~cm}^{-2}\left(688.59 \mathrm{~mA} \mathrm{~cm}^{-3}\right)$, excellent lifespan of $88.20 \%$ capacitance retention after 10,000 cycles at $30 \mathrm{~mA} \mathrm{~cm}^{-2}$ and superior rate capability $\left(94.31 \%\right.$ retention, $2-30 \mathrm{~mA} \mathrm{~cm}^{-2}$ ). This design concept of 3D printing multi-porous current collector with hierarchical active materials provides a novel way to build high-performance 3D microelectrodes.
\end{abstract}

Keywords 3D printing $\cdot$ Supercapacitor $\cdot$ Microelectrode $\cdot$ Copper oxide $\cdot$ Multi-porous current $\cdot$ High areal specific capacitance

\section{Introduction}

The recent boom in microscaled devices, such as microelectromechanical systems (MEMS) [1], wireless and portable electronics [2-4] has remarkably stimulated the demand of

Available online at https://link.springer.com/journal/40195

Electronic supplementary material The online version of this article (https://doi.org/10.1007/s40195-020-01097-x) contains supplementary material, which is available to authorized users.

Yuejiao Chen

cyj.strive@csu.edu.cn

$\triangle$ Libao Chen

lbchen@csu.edu.cn

1 State Key Laboratory of Powder Metallurgy, Central South University, Changsha 410083, China high-performance, miniature and mass-produced electrochemical energy storage devices (EESD) such as water splitting [5], Li-battery [6] and supercapacitor devices [7]. From this viewpoint, supercapacitors with superior power density, fast charge-discharge rate, long cycle lifetime and environmental friendliness have attracted extensive attention [7-11]. To cater for the fast-growing demand of MEMS, microelectrodes with high areal capacity and large rate ability are prerequisite for micro-supercapacitors (MSCs) in limited space, arising from the complex shape and tiny size of MEMS [12-15]. However, it is hard for traditional electrodes such as two-dimensional (2D) planar or film electrodes to meet the above requirements whether in electrochemical performance or low cost for large-scale production [16, 17]. Therefore, achieving an appropriate manufacturing technique for building ordered three-dimensional (3D) architecture, improving the related electrochemical performance and implementing the mass production are of great importance. 
Increase in mass loading by electrodes provides an available route to improve electrochemical capacity in limited space. Lewis and coworkers firstly fabricated thick $\mathrm{LiFePO}_{4}$ (LFP) and $\mathrm{Li}_{4} \mathrm{Ti}_{5} \mathrm{O}_{12}$ (LTO) electrodes for interdigitated Liion micro-battery, displaying an admirable areal capacity of $1.5 \mathrm{mAh} \mathrm{cm}^{-2}$ [1]. Then, Hu et al. [18] successfully fabricated GO/LFP cathode and GO/LTO anode both with the mass loading of about $18 \mathrm{mg} \mathrm{cm}^{-2}$, showing much higher area capacity than that of traditional thin electrodes. Inspired by these, a growing number of researchers pour high attention to various thick electrodes for energy devices, such as lithium-ion batteries [19, 20], sodium-ion batteries [21], lithium-sulfur batteries [22] and supercapacitors [14, 15, 23]. Actually, thick electrodes often obtain good mass loading capacity, but meanwhile may hinder electron/ion transfer because of the long electron/ion transport pathways [24, 25], thus resulting in poor rate ability. So, the utilization of a 3D framework electrode with porous structure may promise both mass loading and ion transport. Additionally, like some common metal foams with disordered macroporous architecture, they are generally employed as 3D current collectors for fast electron/ion transfer [26-28]. Nevertheless, it is commonly difficult to precisely control the pore structure and size, thus resulting in uncertainty of active sites in energy storage. Recently, 3D printing strategy offers new possibilities in energy-related applications. Direct ink writing (DIW), a type of extrusion-based 3D printing technique, breaking through the restrictions of conventional electrode shapes, can be used for the building of 3D-ordered porous skeleton with geometry flexibility and structure scalability by a simple and low-cost process $[14,29,30]$. In this manner, the 3D-printed hierarchical structure can serve as a good scaffold for active material. It can not only facilitate effective electron transport and ion diffusion but also maximize surface area for enhancing mass loading of active materials in restricted space.

In this regard, we demonstrate a fabrication strategy for 3D-printed ordered multi-porous $\mathrm{Cu}$ current collector with a fully controllable design. The 3D-printed $\mathrm{Cu}$ scaffolds can be firmly planted with $\mathrm{CuO}$ nanosheet arrays by an in situ electro-oxidation treatment [31], which has attracted considerable interest in virtue of its desirable capacitance [32], low cost and environmental friendly [33, 34]. Selecting appropriate binder for smooth printing and setting rational program for debinding and sintering are the key factors for this 3D printing process, which determine the construction of selfsupported hierarchical porous $\mathrm{Cu}$ conductive skeleton. As a result, a hierarchically porous 3DP Cu@ $\mathrm{CuO}$ electrode was successfully fabricated, demonstrating an ultrahigh areal capacitance of $1.690 \mathrm{~F} \mathrm{~cm}^{-2}\left(38.79 \mathrm{~F} \mathrm{~cm}^{-3}\right)$ at a large current density of $30 \mathrm{~mA} \mathrm{~cm}^{-2}\left(688.59 \mathrm{~mA} \mathrm{~cm}^{-3}\right)$, and superior rate capability forms the current density of 2 to $30 \mathrm{~mA} \mathrm{~cm}^{-2}$, as well as $88.20 \%$ capacitance retention after 10,000 cycles.
This design concept that combines 3D printing with in situ growth provides a novel pathway to prepare thick electrodes with both high area capacity and large rate capability for other functional EESD.

\section{Experimental}

\subsection{Materials}

The copper powder with an average particle size of $25 \mu \mathrm{m}$ and purity of $99.9 \%$ was purchased from Shanghai Zhili Metallurgy Sales Department. $\mathrm{Cu}$ foam and $\mathrm{Cu}$ foil were purchased from Tianjin Aiweixin Chemical Co. Ltd with thickness of $0.4 \mathrm{~mm}$ and $0.1 \mathrm{~mm}$. Pluronic F127 powder with average $\mathrm{Mw} \sim 12,600$ was purchased from Aladdin. Other chemical reagents like hydrochloric acid $(\mathrm{HCl})$, potassium hydroxide $(\mathrm{KOH})$ and ethanol were of analytical grade. The ultrapure water was pretreated through an ultrapure water system.

\subsection{Fabrication of 3DP Cu@CuO Electrodes}

\subsubsection{Preparation of Copper Ink}

$1.5 \mathrm{~g}$ Pluronic F127 powder was dissolved into $4.5 \mathrm{ml}$ of ultrapure water through a magnetic stirrer in fridge with low temperature (below $10^{\circ} \mathrm{C}$ ) for $12 \mathrm{~h}$ to obtain the transparent homogeneous solution. Highly concentrated copper ink was prepared by mixing $4.5 \mathrm{~g}$ of copper powder with $1.5 \mathrm{~g}$ Pluronic F127 solution in a sealed container using a Thinky AR-100 Mixer. The ink in the container was placed at room temperature at least for $24 \mathrm{~h}$ to ensure stable rheology property.

\subsubsection{D Printing}

3D printing was carried out to build 3D skeletons using a desktop robot (Figure S1). In detail, the printable copper ink was transferred into a $3 \mathrm{ml}$ of transparent plastic syringe with $160 \mu \mathrm{m}$ internal diameter. A DSP501N valve controller with output pressure range from 1 to 100 psi was used to control the printing extrusion pressures between 26 and 32 psi (Pounds per square inch). The printing speed was set as about $6.5 \mathrm{~mm} \mathrm{~s}^{-1}$. And the PTFE (polytetrafluoroethylene) plate was selected as the substrate due to its low surface energy. The printing program of the 3DP Cu lattice $(7 \mathrm{~mm}$ $\times 7 \mathrm{~mm}$ ) can be pre-programed with adjustable setting for the number of layers. 


\subsubsection{Postprocessing}

The printed copper precursors were placed at room temperature to evaporate moisture, followed by binder removal process at $450{ }^{\circ} \mathrm{C}$ for $1.5 \mathrm{~h}$ under $\mathrm{H}_{2} / \mathrm{Ar}$ mixed atmosphere and subsequent vacuum sintering process at $850{ }^{\circ} \mathrm{C}$ for $1.5 \mathrm{~h}$. The 3DP Cu lattices were finally obtained.

\subsubsection{In Situ Growth of CuO Nanosheets on 3DP Cu Lattice, Cu Foam and Cu Foil}

The 3DP Cu lattice was firstly immersed in $1 \mathrm{M} \mathrm{HCl}$ for 5 min to remove surface impurities and then rinsed with deionized water and absolute alcohol several times, followed by drying at vacuum oven. The 3DPCu@CuO microelectrode was prepared by an in situ cyclic voltammetry oxidation process in $50 \mathrm{ml}$ of $6 \mathrm{M} \mathrm{KOH}$ solution using a three-electrode system. The 3DP $\mathrm{Cu}$ lattice was used as the working electrode while the platinum foil and mercuric oxide $(\mathrm{Hg} / \mathrm{HgO})$ electrode served as the counter and reference electrode, respectively. The simple anodization process was carried out in a potential range from 0 to $0.6 \mathrm{~V}$ for different cycles $(500,1000,1500$ cycles $)$ at a scan rate of $50 \mathrm{mV} \mathrm{s}^{-1}$.

For comparison, 3D Cu foam and 2D Cu foil were chosen as current collectors for in situ electro-oxidation growth of $\mathrm{CuO}$. The fabrication processes were the same with that of 3DPCu@CuO microelectrode.

\subsection{Characterization}

The flow behavior and viscoelastic properties of the copper ink were measured in a stress-controlled rheometer (AR2000EX, TA) with a parallel plate $(\varphi=40 \mathrm{~mm})$ at $25^{\circ} \mathrm{C}$. The apparent viscosity of copper ink was carried out through a shear rate and was varied in a logarithmic sweep from 0.1 to $100 \mathrm{~s}^{-1}$. The storage modulus and loss modulus were measured at a fixed frequency with an oscillatory stress sweep from 0.1 to $5000 \mathrm{~Pa}$.

The thermogravimetric tests were carried out in a thermogravimetry (TG, NETZSCH STA 449F3, Germany) at a heating rate of $10{ }^{\circ} \mathrm{C} \mathrm{min}^{-1}$ ranging from room temperature to $1000{ }^{\circ} \mathrm{C}$ under $\mathrm{Ar}$ atmosphere. The structural features were analyzed by scanning electron microscopy (SEM, Nova NanoSEM 230, America) and transmission electron microscopy (TEM, JEM-2100F, Japan). The phase structure was characterized via X-ray powder diffraction (XRD, Rigaku Deskto6, Japan) analysis by using $\mathrm{Cu} K_{\alpha}$ radiation $(\lambda=1.54,056 \AA)$. The sample compositions were measured by X-ray photoelectron spectroscopy (XPS, Thermo ESCALAB 250XI, America).

\subsection{Electrochemical Characterization}

The electrochemical behaviors were carried out on an electrochemical workstation (Ivium-N-stat) through a threeelectrode system. The as-prepared electrodes were used as working electrodes, a platinum foil and $\mathrm{Hg} / \mathrm{HgO}$ served as the counter and reference electrode in $6 \mathrm{M} \mathrm{KOH}$ solution, respectively. Further details about cyclic voltammetry (CV), galvanostatic charge discharge (GCD) and electrical impedance spectroscopy (EIS) can be found in the Support Information.

The area-specific capacitance of the $\mathrm{Cu} @ \mathrm{CuO}$ electrodes can be calculated on the basis of GCD curves by the following equation [35]:

$C_{\mathrm{a}}=\frac{I \int V \mathrm{~d} t}{s V^{2}}$

where $I(\mathrm{~A})$ is the current, $\Delta t(\mathrm{~s})$ is the discharge time, $\Delta V$ $(\mathrm{V})$ is the potential window, and the $\mathrm{s}$ is the surface area of the electrode.

\section{Results and Discussion}

Figure 1 shows the detailed preparation process of the 3DP Cu@CuO electrode. Figure 2 shows the rheological properties of the $\mathrm{PF} 127 / \mathrm{Cu}$ ink and the printing process of the current collector scaffold. The as-prepared PF127 gel and $\mathrm{PF} 127 / \mathrm{Cu}$ ink stored in inverted vials are displayed in Fig. 2a. Both of them were viscous and stuck to the bottom of the vials with the PF127-containing, showing a desirable printing viscosity. Figure $2 \mathrm{~b}$ displays the filaments of the ink extruded by the print machine through the $160-\mu \mathrm{m} \mathrm{noz-}$ zle and the ink can be printed continuously into different integrated scaffolds. After dried sufficient time, the scaffold can be detached from the PTFE plate easily to obtain a 3D-printed microlattice precursor (Fig. 2c). In order to further reflect the printability and stability of ink, we printed unit scaffolds with different layers ranging from 3 to 12 layers on glass slides (Fig. 2d). The heights of the unit scaffolds were measured to be $0.32,0.75,1.16$ and $1.56 \mathrm{~mm}$, respectively, with an expected thickness of $0.16 \mathrm{~mm}$ for each single layer. The expected and actual relationship between the layer numbers and the height of the scaffolds is shown in Fig. 2e. An obvious linear relationship can be established between actual layer numbers and actual height with the actual heights slightly smaller than the expected heights due to shrinkage caused by evaporation of water. Whether smooth for the 3D-printing process depends on the rheological behavior of inks. As shown in Fig. 2f, the apparent viscosity decreases linearly with the increase in shear rate, indicating strong shear-thinning behavior for PF127/Cu ink, 


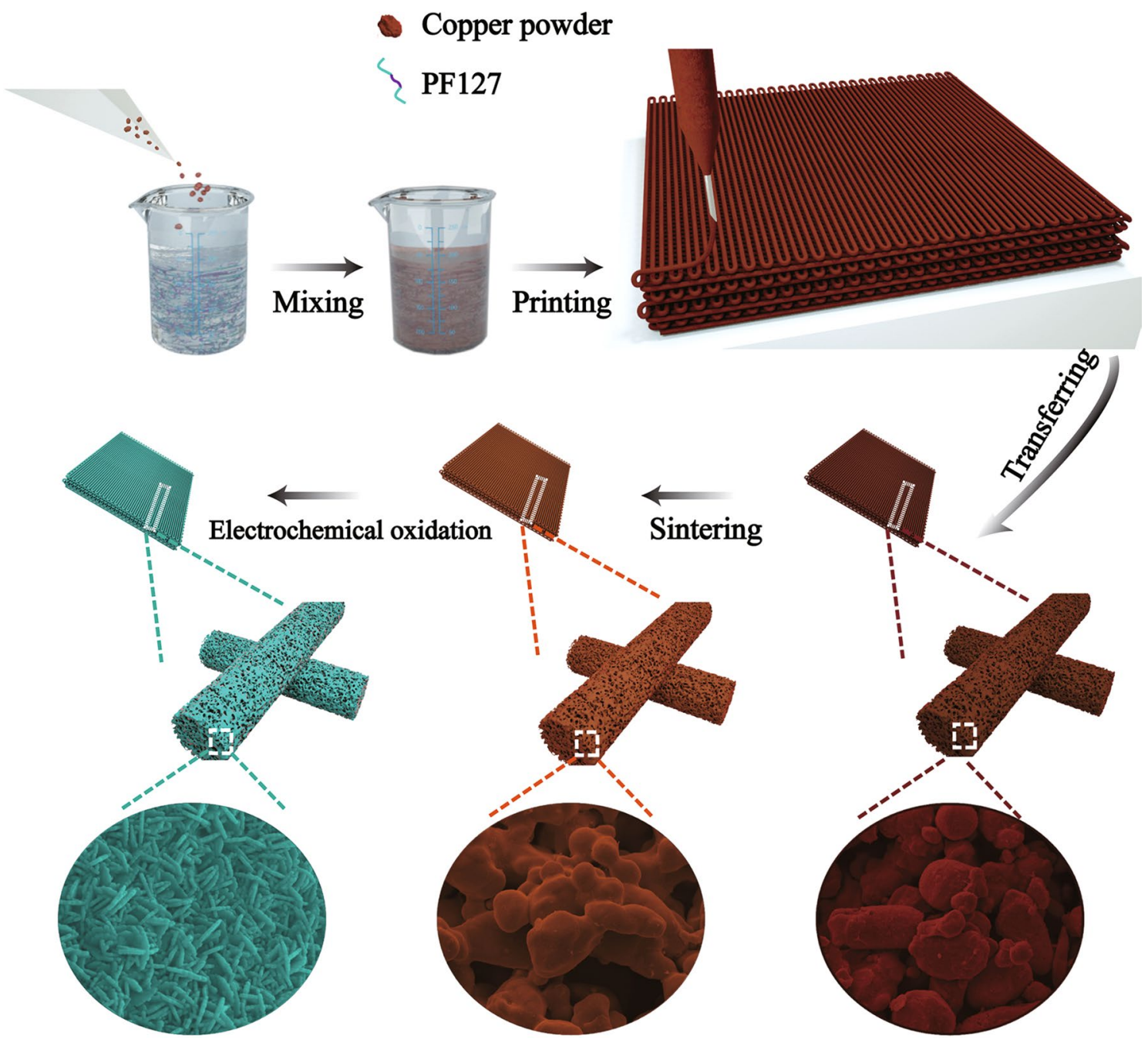

Fig. 1 Schematic illustration of the preparation process of the 3DP Cu@ $\mathrm{CuO}$ electrode

which enables a smooth extrusion from fine nozzles. The shear stress can be estimated by loss moduli, as shown in Fig. 2g. It can be observed that storage modulus $\left(G^{\prime}\right)$ and loss modulus $\left(G^{\prime \prime}\right)$ of the PF127/Cu ink increase by the same trend from $10^{-2}$ to $10^{2} \mathrm{~Pa}$ and then dramatically decrease at higher shear stress, eventually resulting in a lower $G^{\prime}$ than $G^{\prime \prime}$. The plateau $G^{\prime}$ is higher than that of $G^{\prime \prime}$, indicating solidlike response, while it shows a liquid-like behavior when the shear stress increases to higher than $10^{3} \mathrm{~Pa}$. Therefore, the PF127/Cu ink can be extruded smoothly through a micronozzle driven by air pressure, which is desirable for printing of complex 3D structures.

After printing, the 3DP PF127/Cu lattices need heat treatment to get into a real current collector along with debinding and sintering behaviors. The thermal degradation characteristic of the PF127 powder was measured by thermogravimetric analysis. PF127 could be decomposed between 350 and $450{ }^{\circ} \mathrm{C}$ and completely disappeared in the end (Fig. 3a). And the detailed heat treatment program can be found in Fig. 3b. The top-view SEM image shows that multiple orthogonal layers with cylindrical filaments make up the skeleton of 3DP Cu lattices (Fig. 3c). The lattices produce parallel macroporous filaments with the diameter (D) of $\sim 206.5 \mu \mathrm{m}$ and filament space $(L)$ of $\sim 106.8 \mu \mathrm{m}$. No any collapse can be observed in these filaments, demonstrating excellent retentivity of structures. The used $\mathrm{Cu}$ powders have an average size of $25 \mu \mathrm{m}$ for the particles (Figure S2). The magnified images (Fig. 3d) show that $\mathrm{Cu}$ microparticles are individually scattered in the skeleton without interconnecting, which is fragile for the lattice. But the sintering process can bring them together. After heat treating at $850{ }^{\circ} \mathrm{C}$, sintering necks can be formed between copper particles to bridge the isolated islands together. As shown in Fig. 3e, the skeleton with macroporous cylindrical filaments can be completely preserved to form 3DP Cu current collector, with only slightly reducing in the diameters of filaments. From 

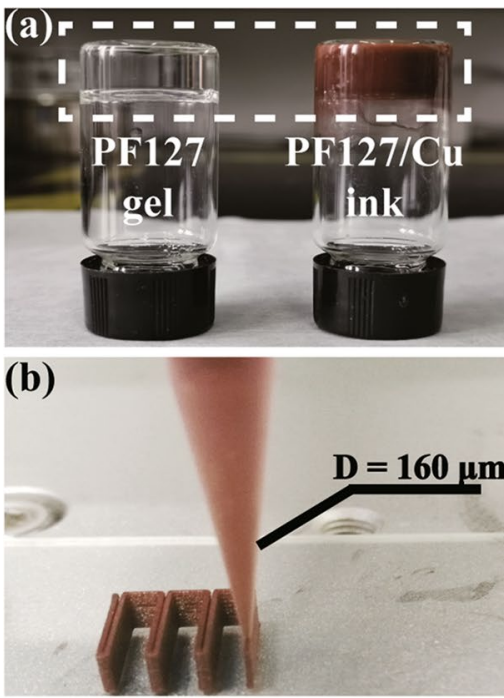

(c)

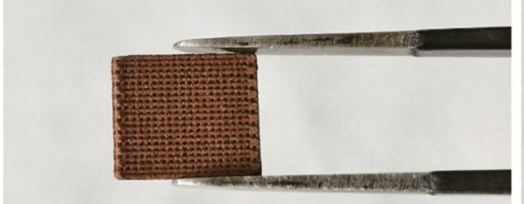

(d)

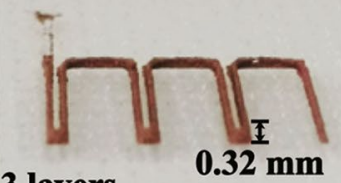

3 layers

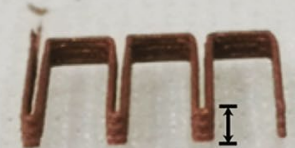

6 layers

$0.75 \mathrm{~mm}$

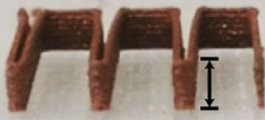

$1.16 \mathrm{~mm}$

9 layers

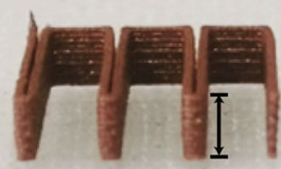

$1.56 \mathrm{~mm}$
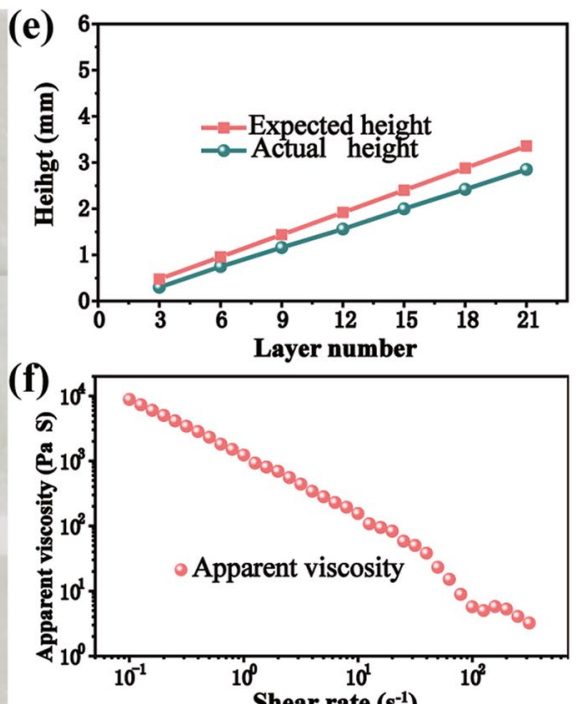

(g)

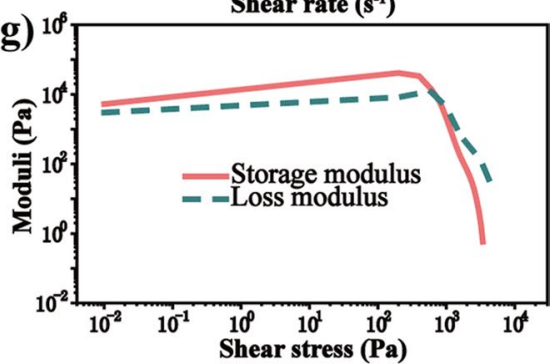

Fig. 2 Digital images to show the printing process and the rheological properties of the ink: a pristine PF127 gel, PF127/Cu ink stored in inverted vials to show the viscosity; $\mathbf{b} \mathrm{Cu}$ current collector printed layer by layer; $\mathbf{c}$ scaffold printed with PF127/Cu ink after drying; d different layers of current collector from 3 to 12 printed layers with PF127/Cu ink; e expected and actual heights of PF127/Cu ink as a function of layer number; $\mathbf{f}$ apparent viscosity as a function of shear rate; $\mathbf{g}$ storage modulus $\left(G^{\prime}\right)$ and loss modulus $\left(G^{\prime \prime}\right)$ as a function of shear stress for the composite ink

the enlarged images (Fig. 3f), sintering necks can be obviously observed between microparticles. At the same time, a large number of pores $(2-20 \mu \mathrm{m})$ are formed to ensure a large surface area for the 3DP Cu current collector, providing enough reaction sites for electrodeposition. Eventually, filament spaces and intergranular pores construct multipores for 3DP Cu current collector. The lateral SEM images of the 3DP Cu in Fig. 3g, h reveal that four printed layers with uniform thickness of $\approx 109 \mu \mathrm{m}$ are consisted of multiple orthogonal cylindrical filaments. The as-obtained 3DP $\mathrm{Cu}$ current collector was strong enough to be handled with a tweezer, as shown in Fig. 3i. Additionally, the element mapping results of 3DP Cu lattice after further sintering are shown in Fig. 3j-1. And the element mapping confirms high purity of the 3DP Cu current collector.

Figure 4 compares the morphologies of $\mathrm{CuO}$ nanosheet arrays planted onto different substrates via in situ CVO process for 1500 cycles. The digital image of the 3DP Cu@CuO electrode can be found in Figure S3. From the low magnified SEM image, it can be seen that the 3DP $\mathrm{Cu}$ possesses ordered macroporous architecture with intergranular pores on filaments, which is benefit for providing more effective sites for uniform growth of the active material (Fig. 4a, b). Thus, the $\mathrm{CuO}$ nanosheets with a thickness of about $45 \mathrm{~nm}$ stand on the whole skeleton completely, arranging in an ordered array with interconnected network (Fig. 4c). It may allow easy diffusion of the electrolyte into the nanosheets matrix and provide large electrochemical active area for energy storage. While random disordered holes exist in $\mathrm{Cu}$ foam without extra pores on the skeleton, which is easy to cause stacking growth of $\mathrm{CuO}$ nanosheets (Fig. 4d-f). For $\mathrm{Cu}$ foil, some nanosheets even fall off from the substrate besides agglomeration behavior due to the smooth surface and insufficient area (Fig. 4g-i). For vivid comparison, the 3DP Cu substrate can be seen as a cube full filled with multiple ordered orthogonal filaments with loose interconnected balls for ultralarge area. The $\mathrm{Cu}$ foam substrate can be seen as a cube only filled with non-porous filaments in disorder arrangement. For $\mathrm{Cu}$ foil substrate, it can only be seen as a compacted cube without any pores inside, showing the smallest active area. The typical element mapping analysis 
(a)

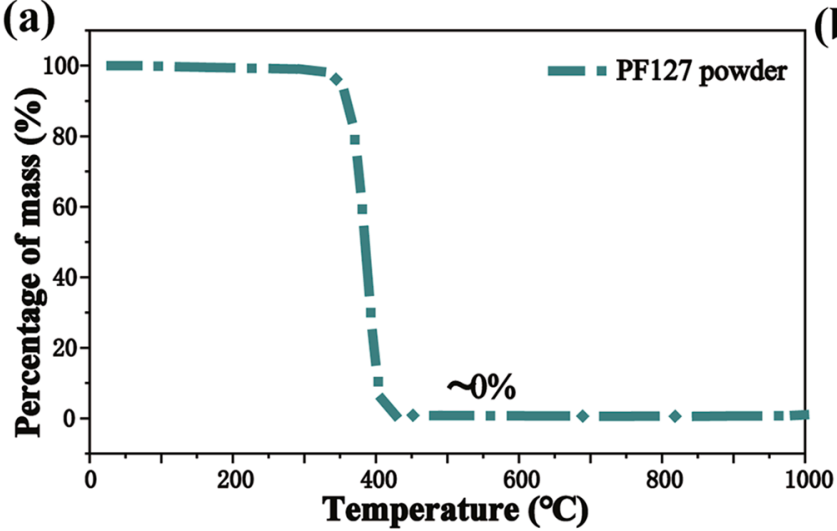

(b) 1

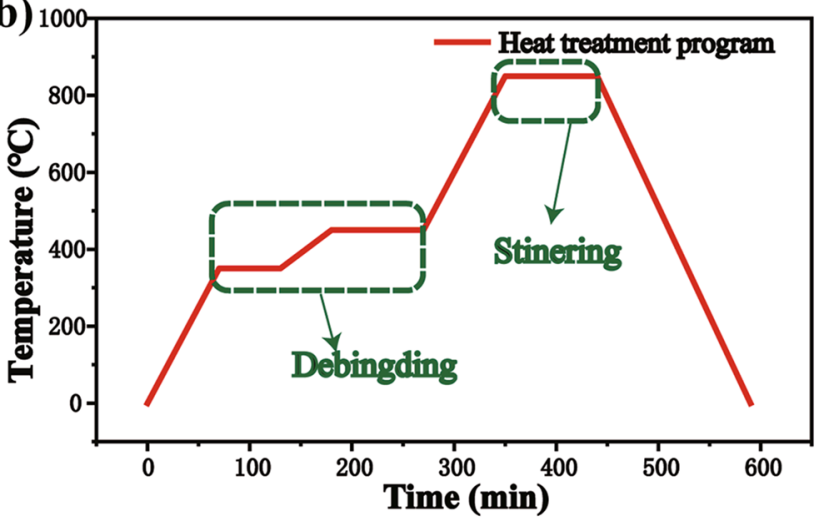

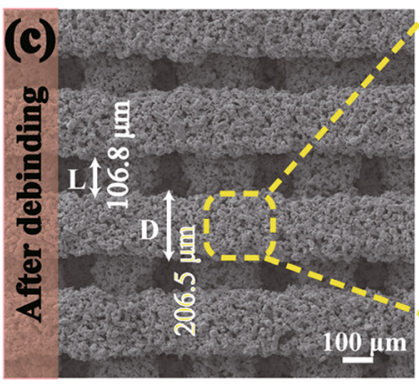

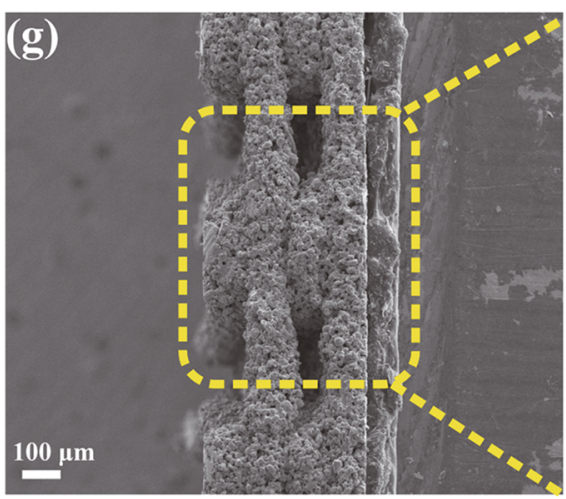

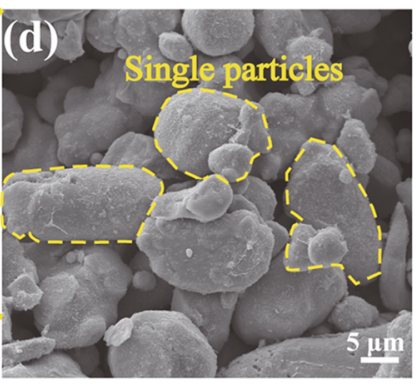

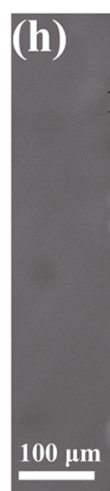

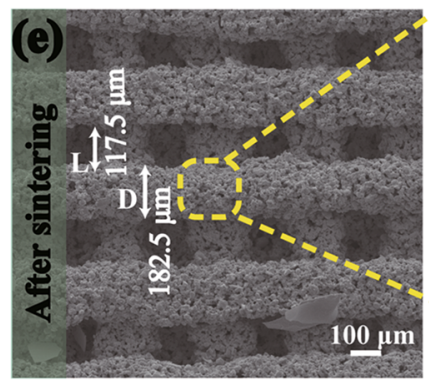

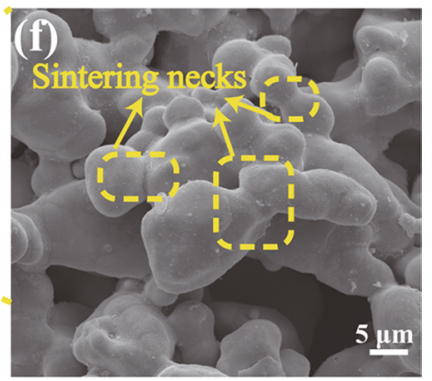

Fig. 3 a TGA curve of the PF127 powder; b curve of the heat treatment program; c-f SEM images of top-view of the 3DP Cu lattice after debinding process; SEM images showing the morphology of the 3DP Cu lattice after further sintering process at different views; $\mathbf{g}$, $\mathbf{h}$ SEM images of lateral-view; $\mathbf{i}-\mathbf{l}$ element mapping results of the 3DP Cu lattice after further sintering

discloses that copper and oxygen are homogeneously dispersed in the 3DP Cu@CuO electrode (Figure S4).

The XRD was employed to confirm the formation of $\mathrm{CuO}$ on $3 \mathrm{DP} \mathrm{Cu}$ (Fig. 5a). The characteristic diffraction peaks at $35.5^{\circ}$ and $38.7^{\circ}$ can match well with the standard XRD pattern of $\mathrm{CuO}$ (JCPDS No.45-0937). And the diffraction peaks at $43.3^{\circ}, 50.4^{\circ}$ and $74.1^{\circ}$ can completely correspond to the standard XRD pattern of Cu (JCPDS No.04-0836). All these confirm that the 3DP Cu@CuO is successfully fabricated without any other impurities. Further surface electronic state information of 3DPCu@CuO was obtained from XPS. The full survey spectrum shows strong signals of $\mathrm{Cu}$ and $\mathrm{O}$ elements (Fig. 5b). High-resolution XPS was used to further analyze the $\mathrm{O} 1 s$ and $\mathrm{Cu} 2 p$ core level spectra in Fig. 5c, d. The peaks of $\mathrm{Cu} 2 p_{3 / 2}$ and $\mathrm{Cu} 2 p_{1 / 2}$ located at 933.8 and
953.5 $\mathrm{eV}$ correspond to $\mathrm{Cu}^{2+}$. At the same time, three satellite peaks at $941.1,943.7$ and $962.4 \mathrm{eV}$ further confirm the existence of $\mathrm{CuO}$. The peaks at 529.49 and $531.31 \mathrm{eV}$ are ascribed to the oxygen atom in $\mathrm{CuO}$ and $\mathrm{Cu}(\mathrm{OH})_{2}$, and the peak at $532.6 \mathrm{eV}$ comes from the water molecule. These results accompanied by the XRD analysis confirm the presence of $\mathrm{CuO}$ in the fabricated electrode. The similar results about $\mathrm{Cu}$ foam@CuO and $\mathrm{Cu}$ foil@ $@ \mathrm{CuO}$ can be found in Figure S5.

To obtain the optimum oxidation cycle number, the CV and GCD curves of the 3DP Cu oxidized at different number of CV cycles were investigated (Fig. 6a, b). Obviously, the capacitance increases rapidly with the $\mathrm{CV}$ oxidation of 3DP Cu from 0 to 1000 cycles, but increases just a little from 1.764 to $1.792 \mathrm{~F} \mathrm{~cm}^{-2}$ with the cycles from 1000 to 1500 . 

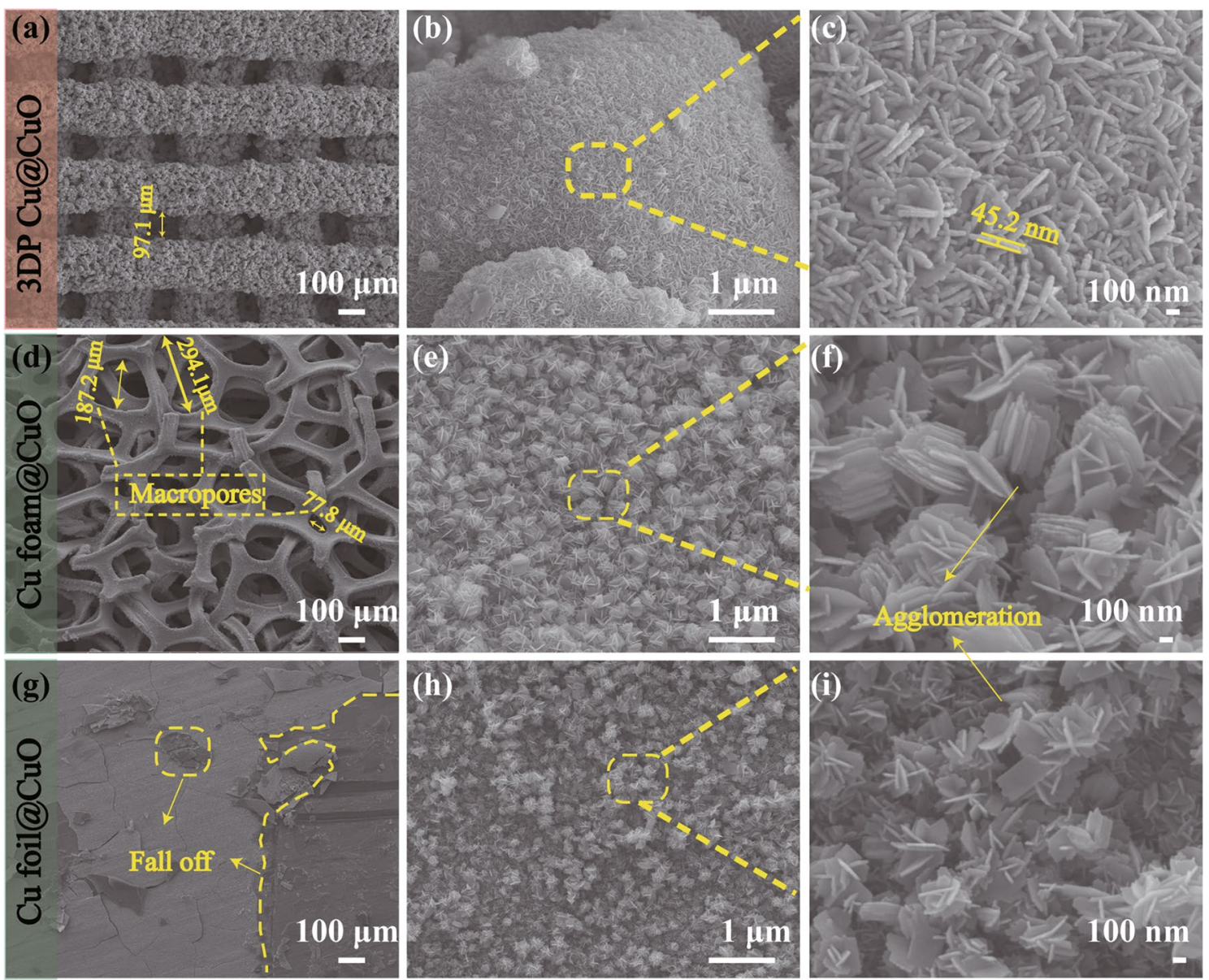

Fig. 4 SEM images to show the morphologies of $\mathrm{CuO}$ nanosheets on different substrates: a-c 3DP $\mathrm{Cu} @ \mathrm{CuO}$ nanosheet arrays; $\mathbf{d}-\mathbf{f} \mathrm{Cu}$ foam@ $\mathrm{CuO}$ nanosheet arrays; $\mathbf{g}-\mathbf{i} \mathrm{Cu}$ foil@ $\mathrm{CuO}$ nanosheet arrays

Considering capacitance and stability, we chose 1500 cycles as the optimum number of CVO cycle. The electrochemical properties of the 3DPCu@CuO electrodes were further investigated through CV, GCD, EIS and long cycle performance tests. Figure 6c shows the typical CV behavior of 3DP Cu@ $\mathrm{CuO}$ electrodes with the potential window of 0-0.6 V at different scan rates from 2 to $50 \mathrm{mV} \mathrm{s}^{-1}$. Apparently, the shape of these $\mathrm{CV}$ curves is different from the ideal rectangular for electrical double-layer capacitors, implying that the capacitance of 3DPCu@CuO mainly originates from the faradaic redox behavior. Distinct peaks cannot be found in the $\mathrm{CV}$ curves due to the incomplete conversion between $\mathrm{Cu}$ (I) and $\mathrm{Cu}$ (II), which have been reported in previous studies [28]. Furthermore, the shape of the $\mathrm{CV}$ curves has not changed much as the scan rate increases, indicating good transport of electrons and ions. The transition between $\mathrm{Cu}$ (I) and $\mathrm{Cu}$ (II) is involved in the following reactions [27]:

$\mathrm{CuO}+\mathrm{H}_{2} \mathrm{O}+2 \mathrm{e}^{-} \rightarrow \mathrm{Cu}_{2} \mathrm{O}+2 \mathrm{OH}^{-}$

$$
\begin{aligned}
& \mathrm{Cu}_{2} \mathrm{O}+\mathrm{H}_{2} \mathrm{O}+2 \mathrm{OH}^{-} \rightarrow 2 \mathrm{Cu}(\mathrm{OH})_{2}+2 \mathrm{e}^{-} \\
& \mathrm{CuOH}+\mathrm{OH}^{-} \rightarrow \mathrm{Cu}(\mathrm{OH})_{2}+\mathrm{e}^{-} \\
& \mathrm{CuOH}+\mathrm{OH}^{-} \rightarrow \mathrm{CuO}+\mathrm{H}_{2} \mathrm{O}+\mathrm{e}^{-}
\end{aligned}
$$

Figure $6 \mathrm{~d}$ shows the charge/discharge curves of 3DP $\mathrm{Cu} @ \mathrm{CuO}$ electrode at different current densities from 2 to $30 \mathrm{~mA} \mathrm{~cm}{ }^{-2}$. The gradual decrease in discharge time with the increase in current density indicates a pseudocapacitive behavior, which is consistent with the $\mathrm{CV}$ results. The corresponding areal capacitances are calculated to be 1.792, $1.790,1.763,1.745,1.727$ and $1.690 \mathrm{~F} \mathrm{~cm}^{-2}(41.13,41.08$, $40.46,40.05,39.64$ and $38.79 \mathrm{~F} \mathrm{~cm}^{-3}$ ) at current densities of $2,5,10,15,20$ and $30 \mathrm{~mA} \mathrm{~cm}^{-2}$. It reveals remarkable rate capacity with $94.31 \%$ retention of the initial capacitance when the current density increases from 2 to $30 \mathrm{~mA} \mathrm{~cm}^{-2}$. Additionally, the 3DP Cu@ $\mathrm{CuO}$ electrode exhibits a superior cycle life with a high capacitance retention of $93.11 \%$ after 5000 cycles, even $88.20 \%$ after 10,000 cycles at a 

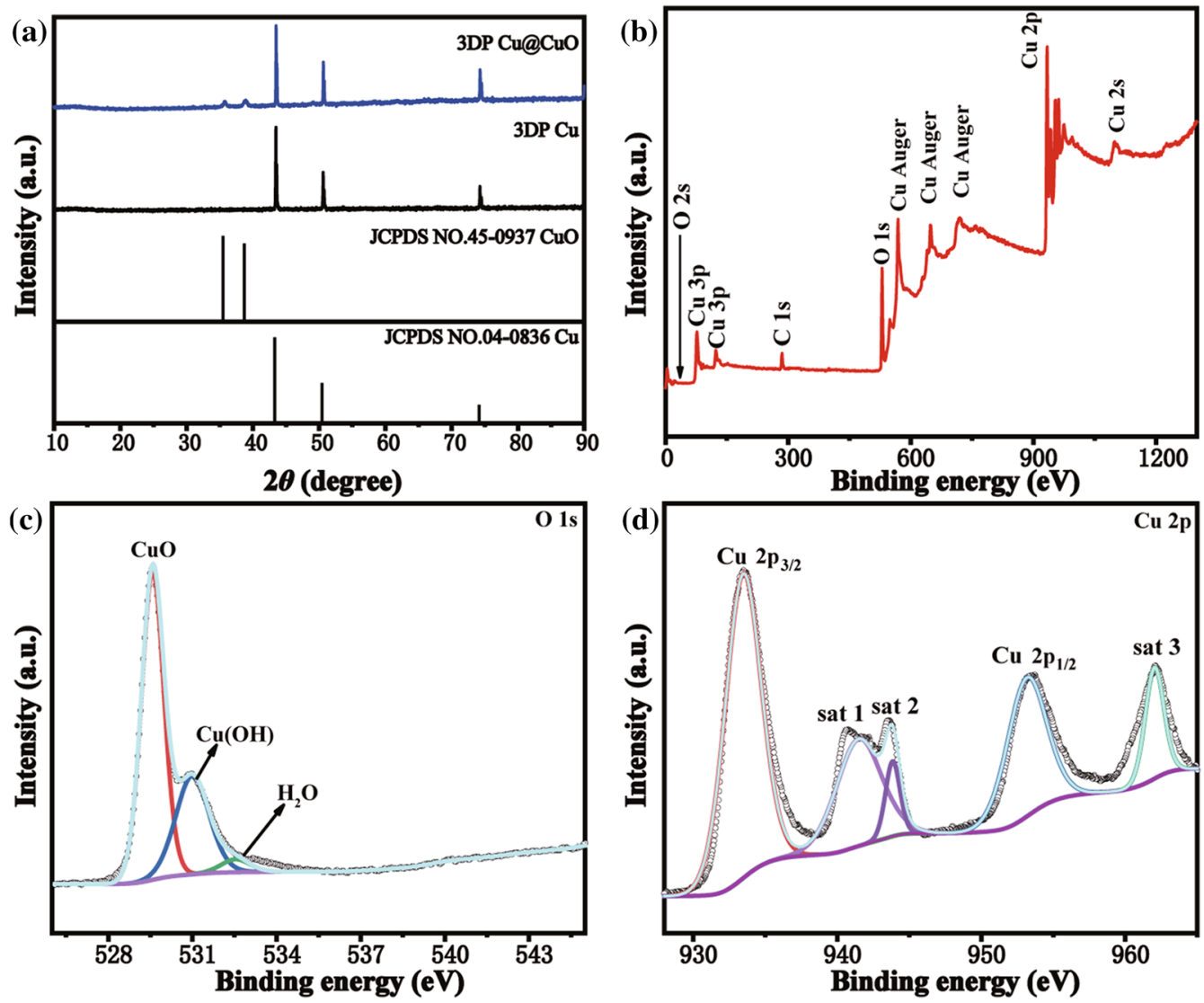

Fig. 5 a XRD patterns of 3DP Cu and 3DP Cu@CuO; b XPS survey spectrum of 3DP Cu@CuO and high-resolution XPS spectra for $\mathbf{c} \mathrm{Cu} 2 p$ and $\mathbf{d} \mathrm{O} 1 s$ of $3 \mathrm{DPCu} @ \mathrm{CuO}$

current density of $30 \mathrm{~mA} \mathrm{~cm}^{-2}$ (Fig. 6e). The inserted SEM image reveals a well retained structure of 3DP $\mathrm{Cu} @ \mathrm{CuO}$ after 10,000 cycles, and the detailed SEM images can be found in Figure S6. Figure $6 \mathrm{f}$ shows GCD curves in detail for the first and last cycle. The Nyquist plots of the electrode before and after cycles are shown in Fig. 6g. The intersection with $x$-coordinate in high-frequency region stands for the electrodes resistance $\left(R_{\mathrm{s}}\right)$. The diameter of the semicircle in the high-frequency region reflects the charge transfer resistance, while the slope of the straight line indicates the ion diffusion resistance [27]. The low charge transfer and ion diffusion resistances of 3DP Cu@CuO lead to the good capacitive nature of the electrodes. From the inset of Fig. $6 \mathrm{~g}$, the values of $R_{\mathrm{s}}$ for the electrode before and after cycles are both around $0.69 \Omega$ with no significant change, implying low intrinsic resistance and good cycle retention. The impedance results indicate excellent pseudocapacitive performance for 3DP Cu@CuO. Figure S7 compares the cycle performance of 3DPCu@CuO electrode with some of the recently reported similar electrodes [27, 28, 33, 36-38]. The current density and cycle number are the two most important factors to the capacitance retention. In this work, the 3DP
$\mathrm{Cu} @ \mathrm{CuO}$ electrode shows wonderful cycle stability at large current density for long cycle number. The detailed data can be found in Table 1 .

To further research the detailed structure of the electrodes before and after 10,000 cycles, TEM, HRTEM, SEAD and EDS element mapping analyses were performed. Figure $7 \mathrm{a}$ shows the TEM image of a single pristine nanosheet scratched from the 3DP Cu@ $\mathrm{CuO}$ electrode before cycles. It displays a fan-like morphology with an uneven outer edge, corresponding to the SEM image. The HRTEM image (Fig. 7b) reveals a lattice fringe spacing of $0.232 \mathrm{~nm}$, corresponding to the (111) facets of $\mathrm{CuO}$. The SAED pattern inset indicates the well-crystallized monocrystalline nature of the obtained $\mathrm{CuO}$. The element distributions of $\mathrm{CuO}$ nanosheets are identified by EDS mapping analysis, demonstrating the homogeneous distribution $\mathrm{Cu}$ and $\mathrm{O}$ elements (Fig. 7c). Figure $7 \mathrm{~d}$ displays the TEM image of a single nanosheet after 10,000 cycles. Comparing with the image before cycle, no obvious change can be found and the fan-like shape feature of the nanosheet is still here which benefit from the nanostructure of $\mathrm{CuO}$ [39]. Moreover, the results about HRTEM, SEAD and EDS mapping images are consistent 

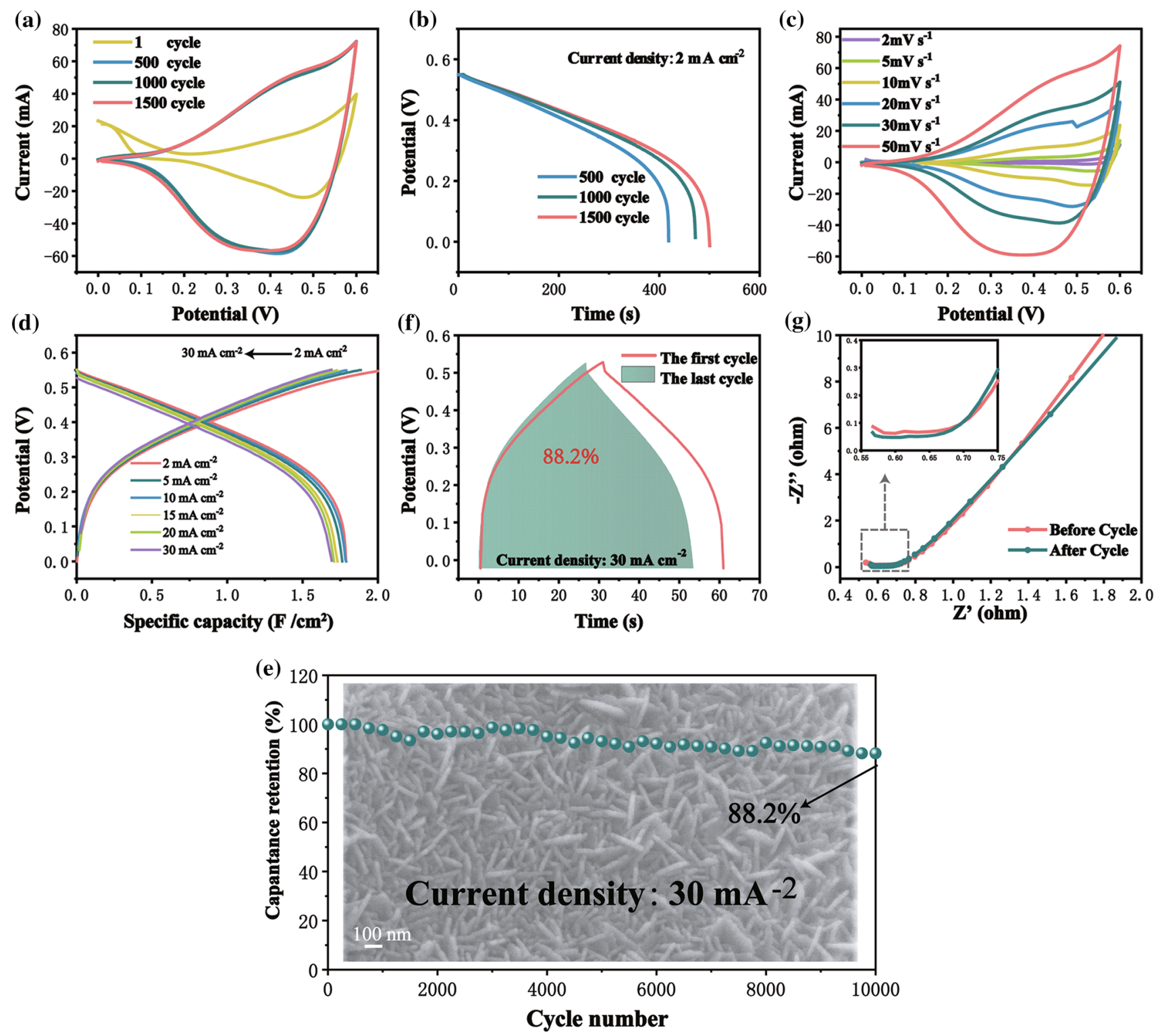

Fig. 6 a CV curves of 3DP Cu@CuO electrode obtained at different CVO cycles; b GCD curves of 3DP Cu@CuO electrode with different CVO cycles; c CV curves of 3DP Cu@CuO electrode with $1500 \mathrm{CVO}$ cycles at various scan rates; $\mathbf{d}$ voltage profiles at various current density from 2 to $30 \mathrm{~mA} \mathrm{~cm}^{-2}$; e cycling performance of 3DP Cu@CuO electrode at a current density of $30 \mathrm{~mA} \mathrm{~cm}^{-2}$, the inset showing the SEM image of 3DP Cu@CuO electrode after 10,000 cycles; f GCD curves of the first and 10,000th cycles at a current density of $30 \mathrm{~mA} \mathrm{~cm}^{-2}$; $\mathbf{g}$ Nyquist plots of 3DPCu@CuO before and after cycle, the inset showing the plots in high-frequency range

Table 1 A comparison of cycle performance with recently reported $\mathrm{CuO}$ electrodes

\begin{tabular}{lllll}
\hline Active material & $\begin{array}{l}\text { Current density } \\
\left(\mathrm{mA} \mathrm{cm}^{-2}\right)\end{array}$ & Cycle number & \multicolumn{2}{l}{$\begin{array}{l}\text { Capacitance reten- } \\
\text { tion }(\%)\end{array}$} \\
\hline CVO Cu@CuO & 20 & 4000 & 96.45 & {$[27]$} \\
NSA-CuO/Ni-foam & 10 & 500 & 93 & {$[33]$} \\
Lotus-like $\mathrm{CuO} / \mathrm{Cu}(\mathrm{OH})_{2}$ & 5 & 5000 & 85 & {$[36]$} \\
$3 \mathrm{D}-\mathrm{CuONA}-\mathrm{Cu}$ & 30 & 54000 & 88.6 & {$[28]$} \\
$\mathrm{Cu}(\mathrm{OH})_{2} / \mathrm{Cu} / \mathrm{Dacron}$ & 2 & 3000 & 90 & {$[37]$} \\
$\mathrm{Cu} @ \mathrm{CoF}-\mathrm{LDH}$ & 10 & 1000 & 96.2 & {$[38]$} \\
$3 \mathrm{DPCu} @ \mathrm{CuO}$ & 30 & $5000 / 10000$ & $93.11 / 88.20$ & This work \\
\hline
\end{tabular}




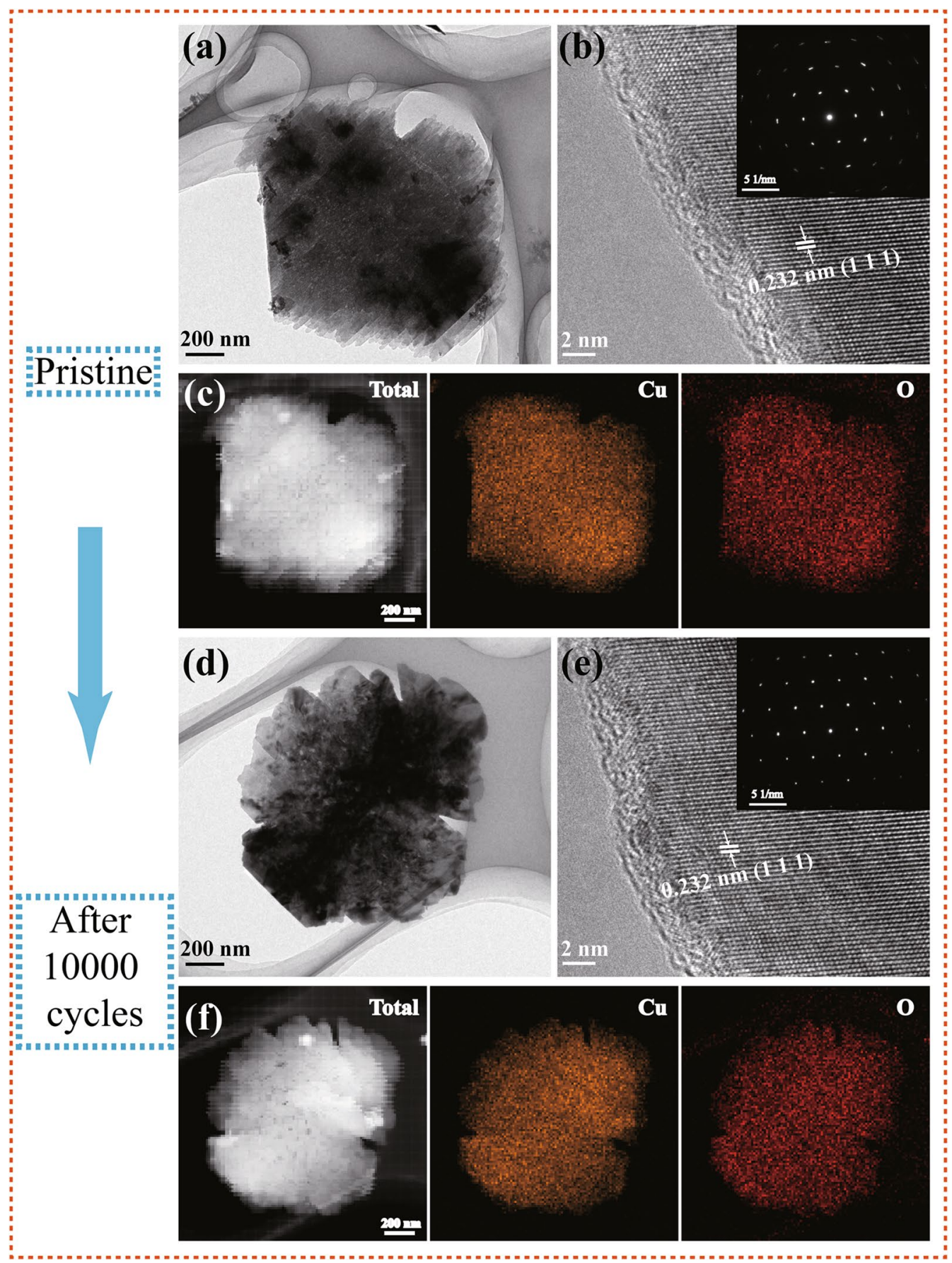

Fig. 7 a TEM image and b HRTEM image of the 3DP Cu@CuO, the inset showing the SAED image; c corresponding EDS elemental mapping images; $\mathbf{d}$ TEM image and e HRTEM image of the 3DP Cu@CuO after 10,000 cycles, the inset showing the SAED image; $\mathbf{f}$ corresponding EDS mapping images for $\mathrm{Cu}$ and $\mathrm{O}$ in the $\mathrm{CuO}$ nanosheet after 10,000 cycles

with that of the electrode before cycle, further certifying outstanding electrochemical cycle stability of 3DP Cu@ CuO microelectrodes.

To investigate the enhancement effect of 3DP Cu current on electrochemical performances, $\mathrm{Cu}$ foam @ $\mathrm{CuO}$ and $\mathrm{Cu}$ foil@ $\mathrm{CuO}$ were prepared under the same conditions as that of 3DPCu@CuO electrode. From the contrastive CV curves
(Fig. 8a) with a potential window of 0-0.6 V under a scan rate of $50 \mathrm{mV} \mathrm{s}^{-1}$, the two comparison electrodes exhibit the same pseudocapacitive behavior, but both less $\mathrm{CV}$ areas than that of 3DPCu@CuO. Figure $8 \mathrm{~b}$ shows GCD curves of the electrodes at the same current density of $2 \mathrm{~mA} \mathrm{~cm}^{-2}$. An obviously longer discharge time can be observed for the 3DP $\mathrm{Cu} @ \mathrm{CuO}$ electrodes. The corresponding area capacitances 

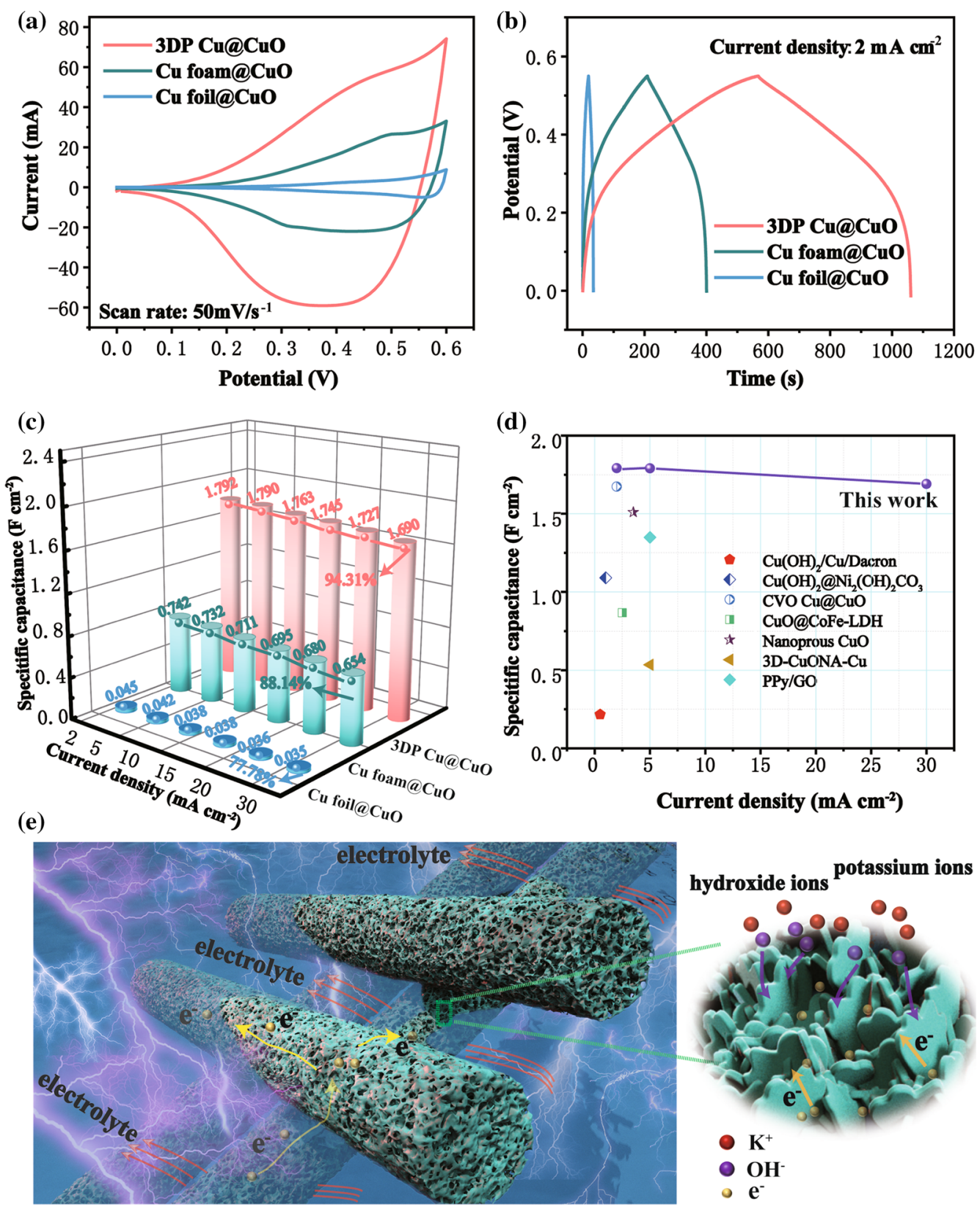

Fig. 8 a CV curves of 3DP Cu@CuO, Cu foam@CuO and $\mathrm{Cu}$ foil@CuO electrodes at a scan rate of $50 \mathrm{mV} \mathrm{s}{ }^{-1}$; b GCD curves of 3DP Cu@ $\mathrm{CuO}, \mathrm{Cu}$ foam@CuO and $\mathrm{Cu}$ foil@CuO electrodes at a current density of $2 \mathrm{~mA} \mathrm{~cm}{ }^{-2}$; c capacitance retention and areal capacitance versus different current densities for 3DP $\mathrm{Cu} @ \mathrm{CuO}, \mathrm{Cu}$ foam@ $\mathrm{CuO}$ and $\mathrm{Cu}$ foil@ $\mathrm{CuO}$ electrodes; $\mathbf{d}$ comparison of specific capacitance; e schematic illustration of the advantages of the 3DP Cu@CuO electrode

can be calculated to be $1.792 \mathrm{~F} \mathrm{~cm}^{-2}\left(41.13 \mathrm{~F} \mathrm{~cm}^{-3}\right)$ for 3DPCu@CuO, $0.742 \mathrm{~F} \mathrm{~cm}^{-2}\left(16.48 \mathrm{~F} \mathrm{~cm}^{-3}\right)$ for Cu foam@ $\mathrm{CuO}$ and $0.045 \mathrm{~F} \mathrm{~cm}^{-2}\left(4.50 \mathrm{~F} \mathrm{~cm}^{-3}\right)$ for $\mathrm{Cu}$ foil @ $\mathrm{CuO}$ electrode, respectively. The obtained 3DP Cu@CuO electrode displays almost 2.5 times larger capacitance than that of $\mathrm{Cu}$ foam@CuO electrode. Such exceptional pseudocapacitive characteristic deeply depends on the hierarchical porous 3D-printed current to provide fully effective active sites for energy storage. The detail CV and GCD curves of $\mathrm{Cu}$ foam@CuO and $\mathrm{Cu}$ foil@ $\mathrm{CuO}$ electrodes at different scan rates and current densities are shown in Figure S8. Rate capability is also a key factor for evaluating the electrochemical property of electrodes. Figure $8 \mathrm{c}$ compares the areal capacitances of the three samples at different current densities. At a current density up to $30 \mathrm{~mA} \mathrm{~cm}{ }^{-2}$, the $\mathrm{Cu}$ foam@ $\mathrm{CuO}$ and $\mathrm{Cu}$ foil@ $\mathrm{CuO}$ maintains only 88.14\% and $77.78 \%$ 
of their original capacitances, respectively, much lower than 94.31\% for 3DP Cu@CuO sample. The corresponding areal capacitances are $0.742 \mathrm{~F} \mathrm{~cm}^{-2}\left(16.48 \mathrm{~F} \mathrm{~cm}^{-3}\right), 0.731 \mathrm{~F} \mathrm{~cm}^{-2}$ $\left(16.24 \mathrm{~F} \mathrm{~cm}^{-3}\right), 0.710 \mathrm{~F} \mathrm{~cm}^{-2}\left(15.78 \mathrm{~F} \mathrm{~cm}^{-3}\right), 0.695 \mathrm{~F} \mathrm{~cm}^{-2}$ $\left(15.44 \mathrm{~F} \mathrm{~cm}^{-3}\right), 0.680 \mathrm{~F} \mathrm{~cm}^{-2}\left(15.11 \mathrm{~F} \mathrm{~cm}^{-3}\right)$ and $0.654 \mathrm{~F}$ $\mathrm{cm}^{-2}\left(14.53 \mathrm{~F} \mathrm{~cm}^{-3}\right)$ with the current densities from 2 to $30 \mathrm{~mA} \mathrm{~cm}^{-2}$ for $\mathrm{Cu}$ foam@CuO electrodes, and 0.035-0.045 $\mathrm{F} \mathrm{cm}^{-2}$ (3.50-4.50 $\left.\mathrm{F} \mathrm{cm}^{-3}\right)$ for $\mathrm{Cu}$ foil @CuO electrodes. Remarkably, the 3DP Cu@CuO electrode delivered higher areal capacitance and larger rate capability than the other two electrodes. Figure 8d compares the areal capacitance of 3DPCu@CuO electrode at different current densities with some of the recently reported similar electrodes [26-28, 37, 38, 40, 41]. Obviously, the 3DP Cu@ CuO electrode demonstrates outstanding areal capacitance at different current densities ranging from 2 to $30 \mathrm{~mA} \mathrm{~cm}^{-2}$.

The superior pseudocapacitance ability derives from the intrinsic properties and unique structures, as illustrated in Fig. 8e. The outstanding performance of 3DP $\mathrm{Cu} @ \mathrm{CuO}$ electrode can be contributed to the following merits: a) the 3D-printed ordered network architectures possesses interconnected macropores, which can establish unobstructed high-speed paths for electron transfer and ion diffusion from bottom to top; b) the uniformly distributed hierarchical pores on filaments greatly enlarge the surface areas of the framework for increasing mass loading of active materials without stacking, ensuring high areal capacitance; c) the well-arranged $\mathrm{CuO}$ nanosheets are directly grown on this 3D skeleton with strong adhesion, greatly reinforcing mechanical integrity and reducing the interfacial contact for enhancing cycling stability. Notably, this electrode architecture engineering strategy can be expected to build other active materials on such microelectrodes for achieving highperformance energy storage.

\section{Conclusion}

In summary, the hierarchical porous 3DP Cu@ CuO electrodes with highly interconnected interior conductive networks were successfully constructed by a facial 3D-printed method. The 3D skeleton was easy to be planted with $\mathrm{CuO}$ nanosheet arrays by in situ CV oxidation treatment. Benefiting from the intrinsic properties and unique structures, the 3DP Cu@CuO electrode exhibits high areal capacitance $\left(1.690 \mathrm{~F} \mathrm{~cm}^{-2}\right.$ at $30 \mathrm{~mA} \mathrm{~cm}^{-2}$ ) and volumetric capacitance ( $38.79 \mathrm{~F} \mathrm{~cm}^{-3}$ at $688.59 \mathrm{~mA} \mathrm{~cm}^{-3}$ ), large rate capability ( $94.31 \%$ of the original capacitance from the current densities of 2 to $30 \mathrm{~mA} \mathrm{~cm}^{-2}$ ), as well as long lifespan (88.20\% after 10,000 cycles, $30 \mathrm{~mA} \mathrm{~cm}^{-2}$ ), which are much better than those of $\mathrm{Cu}$ foam@CuO and $\mathrm{Cu}$ foil@CuO electrodes. The excellent electrochemical properties can be ascribed to the 3D-printed order-interconnected structure with hierarchical pores, benefiting for providing more active sites, ensuring adequate electron transport pathways and shortening diffusion distance between electrolyte ions and substrates. The concept of using 3D-printed designed hierarchical porous $\mathrm{Cu}$ current collector can easily be extended to other metal current substrate/active metal oxide materials for electrochemical energy storage, including lithium-ion batteries, sodium-ion batteries and lithium-sulfur batteries.

Acknowledgements This work was financially supported by the National Natural Science Foundation of China (Nos. 51771236, 51901249 and U1904216), the Science Fund for Distinguished Young Scholars of Hunan Province (No. 2018JJ1038).

\section{References}

[1] K. Sun, T.S. Wei, B.Y. Ahn, J.Y. Seo, S.J. Dillon, J.A. Lewis, Adv. Mater. 25, 4539 (2013)

[2] M.R. Lukatskaya, B. Dunn, Y. Gogotsi, Nat. Commun. 7, 12647 (2016)

[3] P. Simon, Y. Gogotsi, B. Dunn, Science 343, 1210 (2014)

[4] G. Nagaraju, S.C. Sekhar, B. Ramulu, L.K. Bharat, G.S.R. Raju, Y.K. Han, J.S. Yu, Nano Energy 50, 448 (2018)

[5] D. Bae, T. Pedersen, B. Seger, M. Malizia, A.Y. Kuznetsov, O. Hansen, I. Chorkendorff, P.C.K. Vesborg, Energy Environ. Sci. 8, $650(2015)$

[6] M.J. Synodis, M. Kim, S.A.B. Allen, M.G. Allen, Mems Enabled Scalable Fabrication of High Performance Lithium Ion Battery Electrodes. Paper presented at 31st IEEE International Conference on Micro Electro Systems, Belfast, 21-25 January 2018

[7] G. Wang, L. Zhang, J. Zhang, Chem. Soc. Rev. 41, 797 (2012)

[8] C. Zhu, T. Liu, F. Qian, T.Y. Han, E.B. Duoss, J.D. Kuntz, C.M. Spadaccini, M.A. Worsley, Y. Li, Nano Lett. 16, 3448 (2016)

[9] J.R. Miller, P. Simon, Science 321, 651 (2008)

[10] P. Simon, Y. Gogotsi, Nanoscience and Technology: A Collection of Reviews from Nature Journals (World Scientific, Singapore, 2010), p. 320

[11] J. Song, Y. Chen, K. Cao, Y. Lu, J.H. Xin, X. Tao, ACS Appl. Mater. Interfaces 10, 39839 (2018)

[12] L. Zhang, L. Dong, M. Li, P. Wang, J. Zhang, H. Lu, J. Mater. Chem. A 6, 1412 (2018)

[13] L. Ma, H. Fan, X. Wei, S. Chen, Q. Hu, Y. Liu, C. Zhi, W. Lu, J.A. Zapien, H. Huang, J. Mater. Chem. A 6, 19058 (2018)

[14] J. Xue, L. Gao, X. Hu, K. Cao, W. Zhou, W. Wang, Y. Lu, NanoMicro Lett. 11, 46 (2019)

[15] C.J. Zhang, L. McKeon, M.P. Kremer, S.H. Park, O. Ronan, A. Seral-Ascaso, S. Barwich, C.O. Coileain, N. McEvoy, H.C. Nerl, B. Anasori, J.N. Coleman, Y. Gogotsi, V. Nicolosi, Nat. Commun. 10, 1795 (2019)

[16] L. Zhou, W. Ning, C. Wu, D. Zhang, W. Wei, J. Ma, C. Li, L. Chen, Adv. Mater. Technol. 4, 1800402 (2018)

[17] V.G. Rocha, E. Garcia-Tunon, C. Botas, F. Markoulidis, E. Feilden, E. D'Elia, N. Ni, M. Shaffer, E. Saiz, ACS Appl. Mater. Interfaces 9, 37136 (2017)

[18] K. Fu, Y. Wang, C. Yan, Y. Yao, Y. Chen, J. Dai, S. Lacey, Y. Wang, J. Wan, T. Li, Z. Wang, Y. Xu, L. Hu, Adv. Mater. 28, 2587 (2016)

[19] J. Wang, Q. Sun, X. Gao, C. Wang, W. Li, F.B. Holness, M. Zheng, R. Li, A.D. Price, X. Sun, T.K. Sham, X. Sun, ACS Appl. Mater. Interfaces 10, 39794 (2018) 
[20] C. Zhang, K. Shen, B. Li, S. Li, S. Yang, J. Mater. Chem. A 6, 19960 (2018)

[21] J. Ding, K. Shen, Z. Du, B. Li, S. Yang, ACS Appl. Mater. Interfaces 9, 41871 (2017)

[22] K. Shen, H. Mei, B. Li, J. Ding, S. Yang, Adv. Energy Mater. 8, 1701527 (2018)

[23] X. Tang, C. Zhu, D. Cheng, H. Zhou, X. Liu, P. Xie, Q. Zhao, D. Zhang, T. Fan, Adv. Funct. Mater. 28, 1805057 (2018)

[24] H. Zheng, J. Li, X. Song, G. Liu, V.S. Battaglia, Electrochim. Acta 71, 258 (2012)

[25] J. Hu, Y. Jiang, S. Cui, Y. Duan, T. Liu, H. Guo, L. Lin, Y. Lin, J. Zheng, K. Amine, Adv. Energy Mater. 6, 1600856 (2016)

[26] S. Zhu, Z. Wang, F. Huang, H. Zhang, S. Li, J. Mater. Chem. A 5, 9960 (2017)

[27] Y. Liu, X. Cao, D. Jiang, D. Jia, J. Liu, J. Mater. Chem. A 6, 10474 (2018)

[28] J. Huang, H. Li, Y. Zhu, Q. Cheng, X. Yang, C. Li, J. Mater. Chem. A 3, 8734 (2015)

[29] X. Tang, H. Zhou, Z. Cai, D. Cheng, P. He, P. Xie, D. Zhang, T. Fan, ACS Nano 12, 3502 (2018)

[30] P. Jiang, Z. Ji, X. Zhang, Z. Liu, X. Wang, Prog. Addit. Manuf. 3, 65 (2018)
[31] J.J. Teo, Y. Chang, H.C. Zeng, Langmuir 22, 7369 (2006)

[32] Y. Li, X. Chen, L. Li, RSC Adv. 9, 33395 (2019)

[33] G. Wang, J. Huang, S. Chen, Y. Gao, D. Cao, J. Power Sources 196, 5756 (2011)

[34] M. Zhi, C. Xiang, J. Li, M. Li, N. Wu, Nanoscale 5, 72 (2013)

[35] L.Q. Mai, A. Minhas-Khan, X. Tian, K.M. Hercule, Y.L. Zhao, X. Lin, X. Xu, Nat. Commun. 4, 2923 (2013)

[36] Y.K. Hsu, Y.C. Chen, Y.G. Lin, J. Electroanal. Chem. 673, 43 (2012)

[37] S. Lei, Y. Liu, L. Fei, R. Song, W. Lu, L. Shu, C.L. Mak, Y. Wang, H. Huang, J. Mater. Chem. A 4, 14781 (2016)

[38] Z. Li, M. Shao, L. Zhou, R. Zhang, C. Zhang, J. Han, M. Wei, D.G. Evans, X. Duan, Nano Energy 20, 294 (2016)

[39] A. Paolella, R. Brescia, M. Prato, M. Povia, S. Marras, L. De Trizio, A. Falqui, L. Manna, C. George, ACS Appl. Mater. Interfaces 5, 2745 (2013)

[40] S.E. Moosavifard, M.F. El-Kady, M.S. Rahmanifar, R.B. Kaner, M.F. Mousavi, ACS Appl. Mater. Interfaces 7, 4851 (2015)

[41] Z. Wang, Q.E. Zhang, S. Long, Y. Luo, P. Yu, Z. Tan, J. Bai, B. Qu, Y. Yang, J. Shi, H. Zhou, Z.Y. Xiao, W. Hong, H. Bai, ACS Appl. Mater. Interfaces 10, 10437 (2018) 